\title{
Enhanced Bone Apposition to Brazilian Microrough Titanium Surfaces
}

\author{
Samuel Porfírio XAVIER \\ Karen Emi IKUNO \\ Marconi Gonzaga TAVARES \\ Department of Oral and Maxillofacial Surgery and Periodontology, \\ Ribeirão Preto Dental School, University of São Paulo, Ribeirão Preto, SP, Brazil
}

\begin{abstract}
It has recently been reported that machined and microrough (micro) Brazilian titanium (Ti) implants have good production standards. The aim of this study was to evaluate in vivo bone formation around 2 different implant surfaces placed in dog's mandible. Thirty-two screw-typed Ti implants were used in this study. Mandibular premolars were extracted in 8 dogs and, after 12 weeks, 2 machined (Neodent Titamax, Brazil) and 2 micro implants (Neodent Titamax Porous, Brazil) were placed in each animal. Biopsies were taken at 3 and 8 weeks post-implantation and stained with Stevenel's blue and Alizarin red for histomorphometric measurements of boneto-implant contact (BIC), bone area between threads (BABT) and bone area within the mirror area (BAMA). Data were analyzed statistically by two-way ANOVA $(\alpha=0.05)$. While at 3 weeks micro implants exhibited significantly more BIC than machined ones $(55 \pm 12.5 \%$ and $35.6 \pm 15 \%, \mathrm{p}<0.05)$, no significant difference in such parameter was detected at 8 weeks $(51.2 \pm 21 \%$ and $48.6 \pm$ $18.1 \%, \mathrm{p}>0.05)$. There were no significant differences in BABT and BAMA between the implants. Micro surfaces promoted higher contact osteogenesis. These data indicate that this commercial micro Ti implant surface enhances contact osteogenesis at an early post-implantation period when compared to the machined one.
\end{abstract}

Key Words: dental implants, surface microtopography, osteogenesis.

\section{INTRODUCTION}

Implant surface has been recognized to be a critical factor for the achievement of bone formation around titanium (Ti) implants (1). The most important surface properties are topography, chemistry, surface charge, and wettability (2). Surface properties affect processes such as protein adsorption, cell-surface interaction, cell/ tissue formation and development at the bone-to-implant interface, all of which are relevant to the functionality of the fixture (1).

Many studies regarding augmentation in removal torque values (2-4) or increase in bone apposition around Ti implants (2-5) suggested advantage of (micro) surfaces when compared to machined ones (6-8).

In addition to surface topography, surface chemistry is another key variable for peri-implant bone apposition, since it influences surface charge and wet- tability (9). Placko et al. (10) stated that elements and concentration present on implant surfaces vary according to each manufacturer procedure technique and should not be related to success rates.

The aim of this study was to evaluate bone apposition around machined and micro Brazilian Ti implants.

\section{MATERIAL AND METHODS}

This study was approved by the Animal Ethics Research Committee of the University of São Paulo and conducted according to the proposed guidelines.

\section{Implant Surfaces}

Thirty-two self-tapping screw-type Ti implants were used in this study. Sixteen machined Ti implants (Neodent Titamax, Curitiba, PR, Brazil) were used as 
control and compared to 16 micro Ti implants (Neodent Titamax Porous).

\section{Surgical Procedures}

Eight young adult male mongrel dogs weighing approximately $10 \mathrm{~kg}$ were used. The dogs were anesthetized with an intramuscular injection of $2 \%$ Rompun $20 \mathrm{mg} / \mathrm{kg}$ (Bayer, Porto Alegre, RS, Brazil; $0.05 \mathrm{~mL} /$ $\mathrm{kg}$ body weigth) and, after sedation, an intravenous injection of thiopental (Cristália, Itapira, SP, Brazil; 1 $\mathrm{mL} / \mathrm{kg}$ body weight $-20 \mathrm{mg} / \mathrm{kg}$ thiopental diluted in $50 \mathrm{~mL}$ saline) was applied. After local anesthesia with 2\% mepivacaine plus adrenaline 1:100,000 (Dentsply Ind. e Com. Ltda., Petrópolis, RJ, Brazil), full-thickness flaps were elevated bilaterally in the area of the first to fourth mandibular premolars. The teeth were sectioned in a bucco-lingual direction at the bifurcation so that the roots could be individually extracted without damaging the bony walls. After extraction, the sites were submitted to alveoloplasty, gingivoplasty, curettage, and irrigation with saline and sutured with Vycril (Johnson \& Johnson, São José dos Campos, SP, Brazil). According to a strict protocol (5), after 12 weeks, the dogs were submitted to another surgical procedure to place bilaterally $2 \mathrm{Ti}$ implants following the manufacturer's instructions. A total of 4 implants ( 2 micro and 2 machined) were randomized placed in each mandible, 2 in the left side and the other 2 in the right side. The cover screws were placed and the flaps were repositioned to fully cover the implants and the surgical wounds closed with Vycril (Johnson\&Johnson). For all dogs, healing was clinically uneventful following implant installation. At 3 and 8 weeks postimplantation, the dogs were anesthetized as described above (4 animals per period) and the hemimandibles containing the implants were removed and processed for morphological and histomorphometric analysis. After that, the animals were euthanized with a lethal dose of pentobarbital.

\section{Histological Processing}

The bone segments containing the implants were ground sectioned for light microscopy, as previously described (11). Briefly, immediately after harvesting, the bone segments containing the implants were immersed in $10 \%$ formalin buffered with $0.1 \mathrm{M}$ sodium cacodylate $(\mathrm{pH} 7.3$ ) for $48 \mathrm{~h}$ and transferred to a solution of $70 \%$ ethanol and left for $72 \mathrm{~h}$. Bone segments were then dehydrated in graded concentrations of alcohol and embedded in resin (LR White Hard Grade, London, UK). Following polymerization, resin blocks were sectioned with an annular blade using Microslice 2 precision saw (Ultra Tec Manufacturing Inc., Santa Ana, CA, USA) to produce 2 longitudinal mesiodistal sections per implant. Each section was polished, mounted on glass slides and the resulting $40 \mu \mathrm{m}$-thick mounted sections were further ground and polished to a thickness of $20 \mu \mathrm{m}$. Sections were stained with Stevenel's blue and alizarin red S (11) for histological and histomorphometric analyses.

\section{Histological and Histomorphometric Analysis}

Longitudinal sections were used to morphologically evaluate bone and bone marrow tissues adjacent to the implants. The histomorphometric analysis was relative to the medial third of implants, which involved 5 consecutive areas between 6 threads, from the cervical second thread to the apex, bilaterally. In order to evaluate, respectively, the amount of bone at the boneimplant interface and between threads, bone-to-implant contact (BIC) and mineralized bone area between threads (BABT) were determined. In addition, mineralized bone area within mirror area (BAMA) was also determined to evaluate parent bone content outside the threaded area. The mirror area was defined as a symmetric area to the trapezoid between 2 threads, sharing the larger base of the trapezoid (12). For the measurements, images were digitally recorded using a Leica DMLB light microscope (Leica Microsystems, Nussloch, Germany), with N Plan $(\times 2.5 / 0.07, \times 10 / 0.25, \times 20 / 0.40)$ and HCX PL Fluotar $(\times 40 / 0.75)$ objectives, outfitted with a Leica DC $300 \mathrm{~F}$ digital camera (Leica Microsystems). The acquired digital images were analyzed for BIC measurements using the Leica QWin software (Leica Microsystems), whereas BABT and BAMA were determined using ImageJ software, version 1.34s (NIH, Bethesda, MD, USA). Some images were also processed with Adobe Photoshop software (version 7.0.1, Adobe Systems).

\section{Statistical Analysis}

Where appropriate, data were subjected to twoway ANOVA followed by Duncan's multiple range comparison test. Differences at $p<0.05$ were considered statistically significant. 

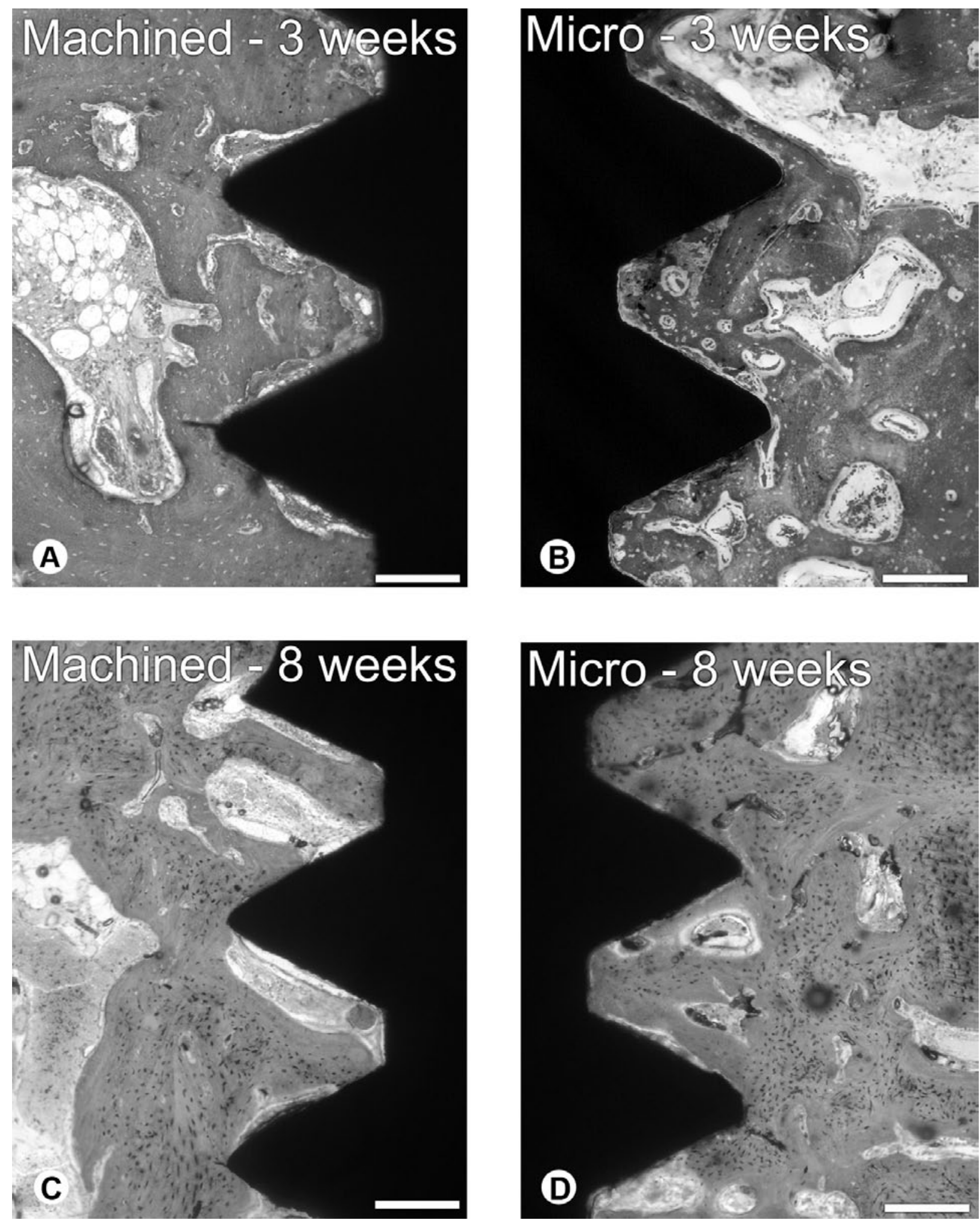

Figure 1. Mesiodistal ground sections of machined $(A, C)$ and micro $(B, D)$ Ti implants and the surrounding connective tissues at 3 $(\mathrm{A}, \mathrm{B})$ and $8(\mathrm{C}, \mathrm{D})$ weeks postimplantation. At 3 and 8 weeks, lamellar bone trabeculae and bone marrow were observed in close contact with machined surfaces $(\mathrm{A}, \mathrm{C})$, whereas a continuous, thin layer of newly formed bone, which was connected to trabeculae of lamellar bone, was observed in intimate contact with micro surfaces. Alizarin red and Stevenel's blue. Bars A,B,C,D = 200 $\mu$ m. 


\section{RESULTS}

\section{Histological Observations}

At 3 weeks (Fig. 1A-B), both micro and machined implants were surrounded by newly formed bone with trabeculae of immature bone lined by well differentiated osteoblasts at the external surface, thus increasing in the thickness of the cortical bone in contact with the implant. Necrotic cortical bone was also found in dispersed areas near implant threads. Although no significant differences in bone morphology on micro and machined implants surfaces were present at 8 weeks (Fig. 1C-D), newly formed bone presented a greater organization and significantly less active osteoblasts and osteoclasts lining the bone matrix while areas of necrotic bone were rarely found. At 3 and 8 weeks, newly formed bone assumed morphology complementary to that of the screw thread on micro implant surfaces. Such finding was not seen on machined implants, which presented areas of the parent, lamellar bone in direct contact with the surface. At 8 weeks, areas of woven bone were par-

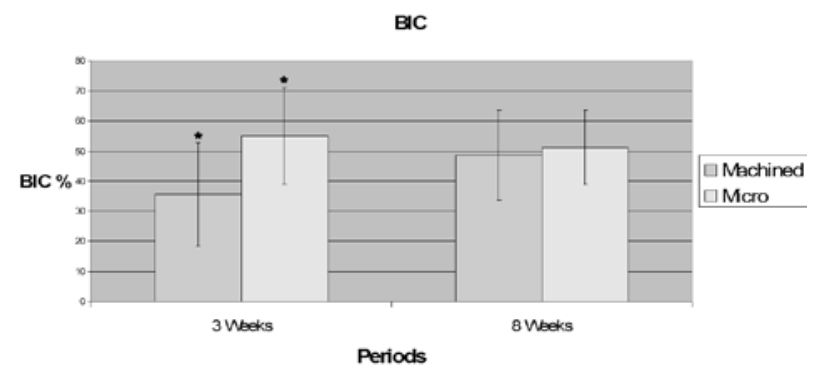

Figure 2. Percentage of bone-to-implant contact (BIC; mean $\pm \mathrm{SD}$ ) for machined and micro surfaces at 3 and 8 weeks.* Significant $(\mathrm{p}<0.05)$.

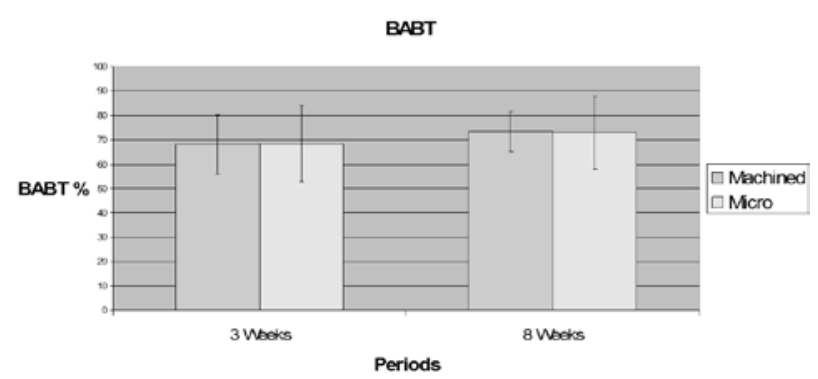

Figure 3. Percentage of bone between threads (BABT; mean \pm SD) for machined and micro surfaces at 3 and 8 weeks. tially replaced by parallel-fibered bone. A continuous apposition of mineralized bone matrix in direct contact with the implant surface was clearly observed only for the micro group, indicating contact osteogenesis. Only rarely were evidences of contact osteogenesis noticed for control implants.

\section{Histomorphometric Analysis}

BIC was significantly higher for the micro implants at 3 weeks, however there was no significant difference at 8 weeks (Fig. 2). For machined and micro implants percentage of BIC was, respectively, 35.6 $\pm 15.0 \%$ and $55.0 \pm 12.5 \%$ at 3 weeks $(p<0.05)$, and $48.6 \pm 18.1 \%$ and $51.2 \pm 21.0 \%$ at 8 weeks $(p>0.05)$. BABT and BAMA were statistically similar $(\mathrm{p}>0.05)$ for both surfaces at 3 and 8 weeks (Figs. 3 and 4). For machined and micro implants percentages of BABT were, respectively, $68.1 \pm 8.4 \%$ and $68.5 \pm 15.0 \%$ at 3 weeks, and $73.5 \pm 15.1 \%$ and $73.0 \pm 17.6 \%$ at 8 weeks (Fig. 3). Percentage of BAMA for machined and micro implants were, respectively, $67.8 \pm 10.6 \%$ and $64.3 \pm$ $14.4 \%$ at 3 weeks, and $69.5 \pm 17.5 \%$ and $68.1 \pm 20.7 \%$ at 8 weeks (Fig. 4).

\section{DISCUSSION}

The results of the present study show that this micro implant surfaces promote more BIC at early periods of osseointegration when compared to machined surfaces, leading to enhancement in contact osteogenesis in a dog mandible model.

Implant surface topography is far the most studied characteristic in oral implants. Despite of the manufacture procedure, it's known that increasing in

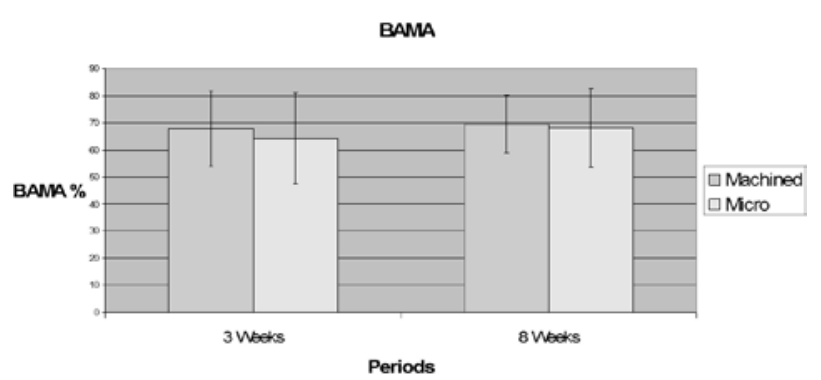

Figure 4. Percentage of bone area within the mirror area (BAMA; mean $\pm \mathrm{SD}$ ) for machined and micro surfaces at 3 and 8 weeks. 
topographic values enhance bone apposition around $\mathrm{Ti}$ implants. Greater surface roughness increases the implant surface area and the potential of fibrin interlocking into implant surface, promoting osteoblast migration and bone matrix secretion to the implant surface. Such events enhance bone-to-implant contact and improve stabilization (13). As commonly observed in published studies regarding topographic surfaces, Neodent's machined implants showed unidirectional striations likely due to the machining process, while micro implants presented porosity aspects probably related to particular surface treatment (14), thus increasing BIC at early periods of osseointegration.

In addition to surface topography, surface chemistry is another important characteristic in osseointegration that can lead a bioinert surface to a bioactive one (15). Cassinelli et al. (16) believe that surface composition has an important effect in cell response (in vitro), and, as a consequence, accurate analysis of the surface chemistry of titanium implants should be an integral part of every study on the biologic response to roughened titanium implant surfaces. Taborelli et al. (17) presented an investigation of the physico-chemical surface properties of cp-Ti submitted to various treatments using auger electron spectroscopy. The authors demonstrated that every sample had a superficial layer of oxidized $\mathrm{Ti}\left(\mathrm{TiO}_{2}\right)$ and less amounts of C, S, Si e Ca as impurities. The acid attacked samples present a subsurface layer which contains hydrogen below the native passivating oxide layer. The different treatments analyzed, influenced surface roughness by preserving the chemical composition and the wettability properties of Ti native oxide surface layer. Castilho et al. (14) demonstrated by $\mathrm{x}$-ray photoelectron spectroscopy (XPS) analysis that Neodent's Ti surface consisted of oxidized titanium (mainly $\mathrm{TiO}_{2}$ ), $\mathrm{C}, \mathrm{O}$ and a few amount of contaminants like N, P and Si. These findings showed no discrepancy in chemical composition when compared to machined MKIII implants and MKIII TiUnite Implants (Nobel Biocare, Gothenburg, Sweden). Furthermore, these data are in accordance with Morra et al. (18) that presented values for Ti (11.8 $\pm 4.9 \%), \mathrm{C}(40.4 \pm 13.7 \%)$ and $\mathrm{O}(39.4 \pm 8.4 \%)$ after XPS analyses on 34 different commercially available titanium dental implants.

It is important to observe that increasing in BIC on Neodent's micro implants at 3 weeks compared to machined ones $(55.0 \pm 12.5 \%$ and $35.6 \pm 15.0 \%$, respectively) is due to direct bone apposition along the implant surfaces, as observed in other studies (2-5). Although strict comparisons between studies cannot be made due to differences in design, implant technology, and analysis, the observations in the present study demonstrate that BIC is in accordance to other studies varying from $52 \%$ to $68 \%$ for plasma-sprayed implants (reviewed in Huang et al.) (19). This study had also shown an unexpected tendency toward a reduction in BIC for the micro implants. Although not significant, such a tendency has also been demonstrated for SLA implants at 6,8 and 12 weeks compared with 4 weeks postimplantation (20) and for SLA modified implants at 8 weeks compared with 4 weeks postimplantation (2).

In contrast, BABT and BAMA showed no statistical difference for machined and micro implants at 3 or 8 weeks. It has been demonstrated that there is a direct significant correlation between BABT and BIC. Huang et al. (19) showed that higher osseointegration was observed in areas of more intra-thread bone, increasing BIC. They also found a correlation between BABT e BAMA although such correlation was not found between BAMA and BIC.

In conclusion, these results showed that this type of micro implants surface have a considerable osteoconductive surface and a higher BIC at early time periods than machined implants. Since it has been shown that higher BIC values have a direct correlation with stability of implants, it suggests that this micro implant surface may be favorable to immediate/early loading implant protocols.

\section{RESUMO}

Estudos recentes demonstram que implantes nacionais de titânio (Ti) usinados e micro-rugosos apresentam padrões adequados de produção. O objetivo deste estudo foi de avaliar a neo-formação óssea in vivo em 2 tipos diferentes de implantes colocados em mandíbulas de cães. Trinta e dois implantes rosqueáveis de Ti foram utilizados neste estudo. Os pré-molares mandibulares de 8 cães foram extraídos e, após 12 semanas, 2 implantes usinados (Neodent Titamax)e 2 implantes micro-rugosos (Neodent Titamax Porous) foram colocados em cada animal. Após 3 e 8 semanas da implantação os espécimes foram biopsiados, corados com Stevenel's blue e Alizarin red e analisados histomorfometricamente quanto à porcentagem de contato-osso-implante (COI), área de osso mineralizado entre as roscas (OMER) e área de osso mineralizado na área em espelho (OMAE). Os resultados foram analisados estatisticamente pelo teste de ANOVA a dois fatores. Os implantes micro-rugosos apresentaram maior COI do que os implantes controle em 3 semanas $(55,0 \pm 12,5 \%$ e $35,6 \pm 15,0 \%$; $\mathrm{p}<0,05)$, enquanto não houve diferença em 8 semanas $(51,2 \pm$ $21,0 \%$ e $48,6 \pm 18,1 \% ; p>0,05)$. Não houve diferença quanto ao 
OMER e OMAE. Esses dados nos indicaram que os implantes micro-rugosos utilizados neste estudo aumentam a osteogênese de contato nos períodos iniciais pós-implantação quando comparados com implantes usinados.

\section{ACKNOWLEDGEMENTS}

This work was supported by The State of São Paulo Research Foundation (FAPESP, Brazil), grant 2005/54037-6 to Samuel Porfírio Xavier. Marconi Gonzaga Tavares was the recipient of a Master degree fellowship from The National Council for Scientific and Technological Development (CNPq), Brazil (134052/20056). Karen Emi Ikuno was the recipient of a Scientific Initiation scholarship from The National Council for Scientific and Technological Development (CNPq), Brazil (111071/2005-4). We would like to thank Sebastião Carlos Bianco, Roger Rodrigo Fernandes and Júnia Ramos (Ribeirão Preto Dental School, University of São Paulo, Brazil).

\section{REFERENCES}

1. Puleo DA, Nanci A. Understanding and controlling the boneimplant interface. Biomaterials 1999;20:2311-2321.

2. Buser D, Broggini N, Wieland M, Schenk RK, Denzer AJ, Cochran DL, et al.. Enhanced bone apposition to a chemically modified SLA titanium surface. J Dent Res 2004;83:529-533.

3. Buser D, Nydegger T, Oxland T, Cochran DL, Schenk RK, Hirt HP, et al.. The interface shear strength of titanium implants with a sandblasted and acid-etched surface. A biomechanical study in the maxilla of miniature pigs. J Biomed Mater Res 1999;45:75-83.

4. Li D, Ferguson SJ, Beutler T, Cochran DL, Sittig C, Hirt HP, et al.. Biomechanical comparison of the sandblasted and acid-etched and the machined and acid-etched titanium surface for dental implants. J Biomed Mater Res 2002;60:325-332.

5. Tavares MG, de Oliveira PT, Nanci A, Hawthorne AC, Rosa AL, Xavier SP. Treatment of a commercial, machined surface titanium implant with $\mathrm{H} 2 \mathrm{SO} 4 / \mathrm{H} 2 \mathrm{O} 2$ enhances contact osteogenesis. Clin Oral Implants Res 2007;18:452-458.

6. Thomas KA, Kay JF, Cook SD, Jarcho M. The effect of surface macrotexture and hydroxylapatite coating on the mechanical strengths and histologic profiles of titanium implant materials. J Biomed Mater Res 1987;21:1395-1414.

7. Larsson C, Thomsen P, Lausmaa J, Rodahl M, Kasemo B, Ericson LE. Bone response to surface modified titanium implants: studies on electropolished implants with different oxide thicknesses and morphology. Biomaterials 1994;15:1062-1074.

8. Groessner-Schreiber B, Tuan RS. Enhanced extracellular matrix production and mineralization by osteoblasts cultured on titanium surfaces in vitro. J Cell Sci 1992;101:209-217.

9. Kilpadi DV, Lemons JE. Surface energy characterization of unalloyed titanium implants. J Biomed Mater Res 1994;28:1419-1425. Erratum in: J Biomed Mater Res 1995;29:1469.

10. Placko HE, Mishra S, Weimer JJ, Lucas LC. Surface characterization of titanium-based implant materials. Int J Oral Maxillofac Implants 2000;15:355-363.

11. Maniatopoulos C, Rodriguez A, Deporter DA, Melcher AH. An improved method for preparing histological sections of metallic implants. Int J Oral Maxillofac Implants 1986;1:31-37.

12. Rosa AL, de Oliveira CS, Beloti MM, Xavier SP, de Oliveira PT Effect of microcapsules containing TAK-778 on bone formation around osseointegrated implants: histomorphometric analysis in dogs. Implant Dent 2006;15:97-103.

13. Davies JE. Mechanisms of endosseous integration. Int J Prosthodont 1998;11:391-401.

14. Castilho GAA, Martins MD, Macedo WAA. Surface characterization of titanium based dental implants. Braz J Physics 2006;36:1004-1008.

15. Franco R de L, Chiesa R, de Oliveira PT, Beloti MM, Rosa AL. Bone response to a $\mathrm{Ca}$ - and $\mathrm{P}$-enriched titanium surface obtained by anodization. Braz Dent J 2008;19:15-20.

16. Cassinelli C, Morra M, Bruzzone G, Carpi A, Di Santi G, Giardino $\mathrm{R}$, et al.. Surface chemistry effects of topographic modification of titanium dental implant surfaces: 2 . In vitro experiments. Int J Oral Maxillofac Implants 2003;18:46-52.

17. Taborelli M, Jobin M, Francois P, Vaudaux P, Tonetti M, SzmuklerMoncler S, et al.. Influence of surface treatments developed for oral implants on the physical and biological properties of titanium. (I) Surface characterization. Clin Oral Implants Res 1997;8:208216.

18. Morra M, Cassinelli C, Bruzzone G, Carpi A, Di Santi G, Giardino $\mathrm{R}$, et al.. Surface chemistry effects of topographic modification of titanium dental implant surfaces: 1 . Surface analysis. Int J Oral Maxillofac Implants 2003;18:40-45.

19. Huang YH, Xiropaidis AV, Sorensen RG, Albandar JM, Hall J, Wikesjo UM. Bone formation at titanium microrough oxide (TiUnite) oral implants in type IV bone. Clin Oral Implants Res 2005; 16:105-111.

20. Abrahamsson I, Berglundh T, Linder E, Lang NP, Lindhe J. Early bone formation adjacent to rough and turned endosseous implant surfaces. An experimental study in the dog. Clin Oral Implants Res 2004; 15:381-392. 